\title{
CONTEÚDO BÁSICO COMUM: ENSINO DE ARTE EM ESCOLAS PÚBLICAS ESTADUAIS DE BELO HORIZONTE/MG
}

RESUMO: Procuramos captar como se dá, na prática, a implementação do Conteúdo Básico Comum, o CBC, de Arte - atual Proposta Curricular do Estado - no primeiro ano do Ensino Médio, em duas escolas públicas estaduais localizadas na cidade de Belo Horizonte/MG. Optou-se por pesquisar somente escolas (pólo de Ensino Médio), uma classificada como Escola Referência, a outra, não. Visamos a mostrar as conclusões relativas à proposta pedagógica em Arte das escolas pesquisadas; o planejamento do arteeducador, verificando as possibilidades de um diálogo entre este e o CBC/Arte; a colaboração dos agentes informadores; bem como a perspectiva do alunado quanto aos aspectos conceituais, procedimentais e atitudinais oferecidos nas aulas de Arte. Longe de se querer, a partir da análise de duas escolas, generalizar os resultados, pretende-se que, ao elucidar questões presentes nas escolas pesquisadas, possam elas servir de reflexão e signifiquem uma contribuição a outras escolas, a professores e pesquisadores.

Palavras-chave: CBC/Arte. Teoria. Prática.

\footnotetext{
* Doutor em Letras pela Universidade Federal do Rio de Janeiro (UFRJ); Professor Responsável e Pesquisador II da Fundação Educacional de Divinópolis. E-mail: ppbessa@oi.com.br

** Mestrado em Educação, Cultura e Organizações Sociais pela Fundação Educacional de Divinópolis (FUNEDI) e Professor da Escola Estadual Dr. Eduardo Góes Filho-Jaboticatubas-MG. E-mail: deleimendes@hotmail.com
} 


\section{COMMON BASIC CONTENTS: TEACHING ART IN PUBLIC SCHOOLS IN BELO HORIZONTE/MG}

ABSTRACT: We try to capture, as it is happening, the practical implementation of "Common Basic Contents, CBC, of Art - the current Curricular Proposal of the State - in the 1st year of secondary school, in two state public schools, both located in the city of Belo Horizonte/MG. We chose to research only schools (two secondary schools, poles apart in performance levels) one classified as a Reference School; the other, not. We aim to draw our conclusions with relation to the pedagogical Art proposal of the school being studied; the art educator's planning process providing the opportunity for exploring what possibilities exist for a dialogue between the school proposal and that of $\mathrm{CBC} /$ Art; the cooperation of all agents able to inform (shed light on) the process; not least, the perspective of the student body, but equally the conceptual, procedural and attitudinal aspects presented in Art classes. Far from intending to generalize results, having only analyzed two schools, the intention is rather to elucidate current (and contemporary) issues in the surveyed schools, such that they can be reflected on and be colocated alongside contributions from other schools, teachers and researchers.

Keywords: CBC/Art; Theory; Practice.

\section{Introdução}

Dentro do Conteúdo Básico Comum (CBC) - Proposta Curricular Contemporânea, busca-se também um Ensino de Arte de qualidade na rede pública estadual de Minas Gerais. Procuramos captar como se dá, na prática, a implementação do $\mathrm{CBC}$ de Arte no primeiro ano do Ensino Médio, em duas escolas públicas estaduais. Para preservar suas identidades, chamaremos uma de escola A e a outra, de escola B, sendo ambas localizadas na cidade de Belo Horizonte/MG.

Optou-se por pesquisar somente escolas (pólo de Ensino Médio), uma referência, escola A; a outra, não, escola B. Longe de se querer, a partir da análise de duas escolas, generalizar os resultados, pretendese que, ao elucidar questões presentes nas escolas pesquisadas, possam elas servir de reflexão e signifiquem uma contribuição a outras escolas, assim como a professores e pesquisadores.

Como resultado de nossa pesquisa de campo, mostraremos as conclusões relativas à proposta pedagógica em Arte das escolas pesquisadas, um comentário sobre o planejamento do arte-educador, verificando as possibilidades de um diálogo entre este e a proposta curricular em que está inserido o CBC/Arte. Ainda apresentaremos a parcela de colaboração dos agentes informadores, membros da comunidade escolar que 
dominam conteúdos artísticos (àqueles que o(a)s professore(a)s têm menos condições para desenvolvê-los aprofundadamente), que possam colaborar no processo de ensino aprendizagem dos alunos, bem como a perspectiva do alunado quanto aos aspectos conceituais, procedimentais e atitudinais oferecidos nas aulas de Arte.

O objetivo geral deste trabalho é o de pesquisar a proposta pedagógica das escolas analisadas sob uma perspectiva interdisciplinar, tendo como referência a atual proposta do estado, para verificar se tais propostas desenvolvem ações que contemplam o conhecimento e as expressões artísticas, de presença cada vez mais frequente na cena contemporânea, no contexto do educando que cursa o nível médio da Educação Básica.

Os objetivos específicos da pesquisa são os seguintes:

(1) analisar, comparativamente, a proposta pedagógica de Arte das escolas e o planejamento de Arte do(a)s professore(a)s, verificando se o desenvolvimento destes, nessas unidades de ensino, está de acordo com os Conteúdos Básicos Comuns estabelecidos na Resolução SEE/MG n. 666, de 7 de abril de 2005;

(2) observar a prática do(a) arte-educador(a), analisando a existência ou não de uma relação entre prática e teoria, verificando, também, se, para o desenvolvimento desta, é levado em consideração o Centro de Referência Virtual do Professor (CRV);

(3) avaliar, comparativamente, os resultados obtidos pelos alunos na avaliação de Arte realizada pelo Programa de Avaliação da Aprendizagem Escolar (PAAE), no ano de 2008.

No percurso de investigação sobre o $\mathrm{CBC}$, três questões tornaram-se relevantes: Em que medida os resultados obtidos no PAAE - Avaliação de Arte - contribuirão para o desenvolvimento de ações que visem a aperfeiçoar o ensino de Arte no nível médio? Em que medida a nova metodologia introduzida pelo CBC auxilia os professores na compreensão de seu papel na formação dos estudantes? Em que medida os arte-educadores apresentam os conhecimentos necessários para possibilitar a amplitude e o entrelaçamento das linguagens artísticas? Essas três questões constituem-se em pontos-chaves na busca pela compreensão do CBC como instrumento de uma política educacional desenvolvida pela Secretaria de Educação do Estado de Minas Gerais, com o intuito de resgatar a qualidade do ensino na educação básica. 
Outro aspecto relevante diz respeito aos estudos desenvolvidos sobre os conteúdos artísticos para a Educação Básica no estado, que, em sua maioria, caracterizam-se por analisar a concepção de conteúdos procedimentais desenvolvidos pelas instituições escolares, analisar comparativamente os conteúdos conceituais e o seu desenvolvimento de acordo com o nível de aprendizagem dos alunos, analisar e destacar projetos culturais, entre outros. O presente estudo pode contribuir para estimular e enriquecer o debate sobre implementação do $\mathrm{CBC}$ e sua fronteira entre o ensino e a aprendizagem das linguagens artísticas no currículo educacional do estado de Minas Gerais.

Visando a desenvolver o estudo proposto, foram selecionadas as escolas estaduais A e B. A primeira, classificada como escola participante do Projeto Escolas-Referência. Já a escola B, por se localizar em uma região de risco e vulnerabilidade social, participa, de modo marcante, do Projeto "Escola Viva, Comunidade Ativa". A opção por apenas duas escolas na realização do estudo justifica-se pelo enfoque dado ao Ensino Médio e por elas oferecerem o ensino apenas para o último nível da educação básica. Além disso, também pela preocupação em garantir a efetiva compreensão dos dados obtidos no andamento do trabalho. Dessa forma, consideram-se a proposta pedagógica, o planejamento do Ensino de Arte e os resultados do PAAE referentes ao ano de 2008.

Para ir a campo, teve-se o cuidado de fazer pela leitura dos documentos relativos à política da Proposta Curricular (CBC) e de vários autores que tratam do ensino de Arte e currículo, buscando elementos para que a análise de situações que foram vivenciadas se dessem com rigor e responsabilidade. Refletiu-se sobre a prática do professor diante da Proposta Curricular - Arte para as escolas públicas estaduais de Minas Gerais, culminando também na análise desse novo "modelo curricular", sua extensão, a possibilidade de um trabalho interdisciplinar, os conteúdos e suas expressões pertinentes a cada linguagem artística e a forma como estão sendo trabalhados.

Outra etapa da pesquisa deu-se por meio da análise de conteúdo, consistindo na investigação dos documentos enviados às EscolasReferências e às demais pela SEE-MG, documentos da própria SEE-MG, os PCN, o CBC e o PNE. Os documentos enviados às ER datam de 2003, período em que o projeto envolveu somente a direção das escolas; em 2004, foi o momento da discussão nas ER e, a partir de 2005, houve a 
implementação dos projetos desenvolvidos pelas próprias ER e o envio do CBC para todas as escolas de Belo Horizonte e demais escolas públicas estaduais mineiras, até a atualidade, em que continua acontecendo a implementação do CBC.

Foi estabelecido um estudo comparativo entre o CBC e os PCN de Arte do Ensino Médio, detendo-se mais nas partes que tratam especificamente sobre o primeiro ano do nível médio. Segundo documentos, o CBC foi elaborado com base nos PCN (MINAS GERAIS, 2005a, p. 5). Esses, por sua vez, foram propostos com a finalidade de nortear a elaboração das propostas pedagógicas das escolas e é compreensível e recomendável que norteiem o CBC. Porém, há semelhanças e distanciamentos a serem considerados na análise de ambos os documentos. As semelhanças possibilitaram fazer um estudo mais crítico do $\mathrm{CBC}$, tendo como subsídios as pesquisas já realizadas sobre os PCN.

Nessa pesquisa, obteve-se autorização para sua realização junto aos diretores escolares, professore(a)s de Arte e da Superintendente Regional de Ensino da Metropolitana C, sediada em Belo Horizonte. O projeto foi aprovado por Comitê de Ética em Pesquisa. Os diretores escolares, professores e a superintendente de ensino foram contatados por telefone ou via ofício. A opção por professores que ministram aulas para o primeiro ano do ensino médio deve-se à abrangência de carga horária estabelecida pela Resolução SEE/MG n. 1025/2007.

Alguns elementos influenciaram na escolha sobre qual(ais) bimestre(s) observar. Os professores, em geral, precisam de um tempo para conhecer suas turmas, estabelecer uma relação com o(a)s aluno(a)s, propor um contato didático, enfim, conhecer e fazer-se conhecido do(a)s mesmo(a)s. Esse período inicial dá-se, em geral, no mês de fevereiro, parte do primeiro bimestre, o qual muitas vezes tem recessos longos, como o do Carnaval e o da Semana Santa, tornando-o um pouco mais conturbado e, talvez, menos produtivo. O quarto bimestre, por sua vez, pela situação de fim de ano letivo, da existência de determinado número de alunos já aprovados, além dos dias reservados às recomposições que porventura venham a ser necessárias para o cumprimento do calendário escolar e por outras peculiaridades, torna-o menos atrativo para esta pesquisa. Portanto, foram considerados o segundo e o terceiro bimestres (entre maio e setembro) como mais adequados para a pesquisa, aproveitando-se melhor o período de observação, respeitando ainda a liberdade do professor, sujei- 
tando-o ao mínimo de incômodo possível com a presença de pesquisador em sala de aula. Por isso, o período de permanência em campo deu-se do início de agosto ao final de outubro do ano de 2009. Esse período possibilitou, como esperado, que o(a)s professore(a)s abordasse(m) pelo menos um tópico de conteúdo de maneira completa, viabilizando acompanhar importantes etapas no processo de ensino-aprendizagem, compreendendo a abordagem, o desenvolvimento e a avaliação.

Somente a observação das aulas não seria suficiente para a pesquisa, por isso foram utilizadas também entrevistas semiestruturadas com professore(a)s, especialistas e aluno(a)s, uma vez que elas permitem ao entrevistado organizar suas respostas de forma mais confortável. Tais entrevistas consistem em questões que abordam o tema sob perspectiva mais ampla, evitando respostas simplificadas e evasivas, sendo utilizado um roteiro de entrevista.

Sobre a entrevista semiestruturada, Trivinos considera que

mantém a presença consciente e atuante do pesquisador e, ao mesmo tempo permite a relevância na situação do ator. Este traço da entrevista semi-estruturada, segundo modo de pensar, favorece não só a descrição dos fenômenos sociais, mas, também sua explicação e a compreensão de sua totalidade, tanto dentro de sua situação específica como de situações de dimensões maiores. De toda maneira, diante dessas últimas situações, é necessário lembrar que os instrumentos de coletas de dados não são outra que 'a teoria em ação', que apóia a visão do pesquisador (TRIVINOS, 1987, p. 146).

Além dos momentos de entrevistas semiestruturadas, devidamente programados, aconteceram diversos "momentos não-estruturados". Foram momentos de conversas informais com os professores pesquisados, com outros professores e com a direção da escola, nos corredores, na sala dos professores e nos arredores da escola. Todos os momentos que pudessem contribuir para o resultado da pesquisa foram considerados, percebendo-se os acontecimentos e atitudes que fornecessem elementos adicionais que não têm como ser obtidos somente com a observação em sala de aula. A atitude dos professores fora da sala de aula, nas conversas com os colegas, diz muito a seu respeito e pode elucidar a proximidade existente entre seu discurso e sua prática.

As entrevistas gravadas foram ouvidas várias vezes e, depois, parte a parte, para que fossem transcritas na íntegra. Seus registros, soma- 
dos aos demais, deram origem a um documento com 92 páginas, cuja finalidade é facilitar o trabalho realizado na fase de análise. Conforme Augusto (2007, p. 66),

a análise de dados é caracterizada como um momento no qual as informações podem ser agrupadas, segundo uma categorização dos dados coletados. As análises devem permitir que a realidade seja desvendada e os questionamentos propiciados pelos objetivos possam ser respondidos (AUGUSTO, 2007, p. 66).

No tratamento dos dados coletados, utilizou-se a análise de conteúdo para o entendimento e a compreensão do material de pesquisa obtido nas entrevistas. Nesse contexto, Bardin esclarece que a análise de conteúdo se caracteriza como

um conjunto de técnicas de análise das comunicações visando obter, por procedimentos sistemáticos e objectivos de descrição do conteúdo das mensagens, indicadores (quantitativos ou não) que permitam a interferência de conhecimentos relativos às condições de produção/recepção (variáveis inferidas) destas mensagens (BARDIN, 2008, p. 44).

O primeiro passo para iniciar o trabalho com os dados foi ler exaustivamente as entrevistas, visando a definir uma categorização. Em outras palavras, buscar a classificação dos elementos dos conjuntos por diferenciação e, posteriormente, por reagrupamento das informações obtidas com as entrevistas. Essa seleção foi baseada em critérios definidos previamente, conforme Bardin (2008) e Franco (2007).

Assim, de maneira esquemática, o trabalho com os dados obtidos por meio das entrevistas organizou-se a partir dos seguintes procedimentos:

(a) leituras e releituras das respostas dos diferentes sujeitos;

(b) compreensão e análise das respostas dadas pelos diferentes sujeitos;

(c) categorização das respostas dos diferentes sujeitos;

(d) comparação das respostas dos diferentes sujeitos aos mesmos itens;

(e) análise vertical das respostas, por meio de elaboração de uma matriz na qual, na linha horizontal, encontram-se as respostas e, na vertical, os sujeitos da pesquisa;

(f) reagrupamento das respostas em categorias amplas. 
Franco (2007) afirma que a categorização das entrevistas é uma operação de classificação de elementos constitutivos de um conjunto por diferenciação, seguida de um reagrupamento baseado em analogias, segundo critérios definidos. A matriz foi construída para realização da análise de conteúdo, respeitando-se cada segmento (professor-aluno-especialista), sendo composta por:

Segmento 1 - Professor(a) de Arte A e B, tendo duas linhas e nove colunas;

Segmento 2 - Especialistas de Ensino A e B, tendo duas linhas e nove colunas;

Segmento 3 - Alunos e Alunas: A1 e A2, B1 e B2, C1 e C2, D1 e D2, E1 e E2, F1 e F2, G1 e G2, H1 e H2, I1 e I2, J1 e J2, tendo vinte linhas e nove colunas, sendo um conjunto de quatro pessoas (alunos e alunas) para representar cada letra expressa.

$\mathrm{Na}$ sua representação, nas colunas identificadas pelas letras de "A-J", estão os participantes do estudo. Nas linhas, encontram-se as respostas dadas pelos entrevistados, sendo que o algarismo arábico refere-se às questões do roteiro da entrevista. A matriz permite identificar as convergências e divergências nas respostas dadas pelos diferentes sujeitos.

Foram usados também recursos auxiliares como gravação de áudio de algumas aulas, fotografias de eventos artísticos e culturais que ocorreram durante o período da pesquisa, bem como o cotidiano da sala de aula, com a devida aprovação prévia para tal. Esses elementos foram importantes quando do distanciamento para análise das anotações de campo, na retomada das questões relevantes, elucidando o que foi vivenciado.

\section{Pesquisa de campo}

Agora serão apresentados e discutidos os resultados obtidos na pesquisa de campo, por meio dos procedimentos já mencionados. Serão mostradas as conclusões da análise da proposta pedagógica das escolas públicas estaduais A e B, ambas de Belo Horizonte/MG. Em seguida, será feito um comentário sobre o planejamento do(a) arte-educador(a), 
verificando se existe um diálogo entre este e o CBC/Arte. Será apresentada também qual é a parcela de colaboração dos agentes informadores da comunidade na implementação dos conteúdos básicos, como é estabelecido pela atual proposta. E, ainda, a perspectiva do alunado quanto aos aspectos conceituais, procedimentais e atitudinais na aprendizagem dos conteúdos artísticos estabelecidos para o Ensino Médio.

\section{A Proposta Pedagógica e o trânsito do CBC de Arte nas escolas estaduais $A$ e $B$ de Horizonte/MG}

Ressaltar a importância da implementação dos conteúdos artísticos no Ensino de Arte, em consonância com a operacionalização da proposta pedagógica das escolas, é um legado dos $\mathrm{CBC}$ que remete às formulações educacionais, especificamente do estado de Minas Gerais, de natureza mais sistematizada.

Nota-se que essa proposta, referente ao componente curricular abordado na pesquisa, ainda não é organizada sistematicamente nas escolas em estudo. As especialistas de ensino (supervisoras educacionais) relataram dificuldades existentes para que haja articulação harmônica entre o ensino e a aprendizagem dos conteúdos e suas linguagens artísticas. $\mathrm{O}$ depoimento da especialista A exemplifica essa situação: "O professor de Arte às vezes deixa a desejar e eu percebo que ele encontra dificuldades para ministrar alguns conteúdos, como, por exemplo, os conteúdos de música". Já a especialista B salienta que "as aulas de Arte precisam melhorar porque o $\mathrm{CBC}$ chegou para ficar e, também, para incrementar as habilidades dos alunos, mas eu penso que uma das dificuldades do professor de Arte é executar os conteúdos e a prática de dança e de música".

Ao analisar o depoimento das especialistas de ensino, verifica-se que existem situações que dificultam, de fato, o trânsito do $\mathrm{CBC}$ de Arte nas escolas de Ensino Médio e a falta de um entendimento mais acurado das relações transversais e interdisciplinares que a arte estabelece e que a proposta curricular em questão possibilita.

Ao se ampliar essa discussão para a prática de sala de aula, abordando os meios com que os professores se organizam para tratar do assunto, verifica-se que há fragmentação no desenvolvimento do ensino e da aprendizagem dos conteúdos propostos pelo CBC. Os professores 
envolvidos na pesquisa afirmam e apontam as dificuldades que contribuem para a realização parcial do trabalho desenvolvido no cotidiano das aulas de Arte. $\mathrm{O}(\mathrm{A})$ professor(a) $\mathrm{A}$, mais ligado às artes visuais, entende que o ensino de Arte é amplo e engloba, para fins de estudo, no nível médio da Educação Básica, cinco áreas específicas: artes audiovisuais, artes visuais, dança, música e teatro, porém, ressalta: "Eu tenho maior êxito na área de artes visuais, pois a mesma está acoplada à licenciatura e à história".

$\mathrm{O}$ (A) professor(a) B também demonstrou mais interesse pelas artes visuais, o que, também, tem a ver com sua formação e habilitação específica no curso de graduação e especialização em Arte. Isso atende parte do que é proposto pelo próprio $\mathrm{CBC}$, quando salienta os tópicos obrigatórios que são referenciais para que o professor aborde os assuntos. Ressalte-se que, entre eles, "o professor poderá escolher os conteúdos que têm mais condições para desenvolver aprofundadamente" (MINAS GERAIS, 2008, p. 43), com o objetivo de contribuir significativamente para a aprendizagem dos alunos em Arte.

A informação dos alunos com relação ao conhecimento da nova proposta curricular, CBC de Arte, foi apontada por cerca de $85 \%$ dos respondentes, tendo esses afirmado ter ouvido falar muito pouco e sem explicações consistentes, enquanto $10 \%$ dos pesquisados só ouviram falar quando ingressaram no Ensino Médio e os outros 5\% relataram que nunca ouviram falar dessa proposta.

Diante do exposto, o que se verifica, a partir dos resultados, é que o sujeito principal do processo ensino-aprendizagem ainda conhece muito pouco sobre o trânsito do $\mathrm{CBC}$ no interior das escolas, bem como a importância e a articulação dele como proposta curricular entrelaçada pela contextualização e pela interdisciplinaridade. Além disso, é perceptível a falta de um diálogo consistente e abrangente em relação à proposta, por parte dos corpos administrativo, pedagógico, docente e discente. E isso é prejudicial à operacionalização da proposta pedagógica da escola, que, por sua vez, exige de cada pessoa a busca e o sentido mais profundo da sua presença na escola e do significado de sua ação nela e da própria existência dessa instituição.

A fala de um grupo de alunos e alunas, representados pela letra $\mathrm{C}_{1}$, afirma a falta de aproximação entre estes, a escola e a proposta curricular: "Nós já chegamos até aqui e nunca ouvimos falar no CBC, parece 
ser uma coisa boa e legal, já que o nosso governo do estado está implantando para nós".

Apesar de o Sistema Educacional considerar essa proposta curricular como um importante instrumento para a melhoria da qualidade da Educação Básica no estado de Minas Gerais, não há momentos dedicados à realização de discussão e/ou estudos que possam melhorar o entendimento do professorado com relação à proposta. Assim, torna-se difícil sua implementação. Saviani (1996) destaca que qualquer sistema implica: intencionalidade, unidade, variedade, coerência interna e coerência externa.

Ao verificar a viabilidade e a possibilidade de os professores terem recebido subsídios necessários da SEE/MG que pudessem contribuir com a implementação eficaz da nova proposta curricular de Arte para o Ensino Médio, foi detectado pelo(a) profesor(a) A o seguinte:

Não! O que nos foi encaminhado pela SEE/MG é uma pequena apostila que fala de uma forma bem sucinta do que é a Proposta Curricular, nem mesmo no site do Centro de Referência Virtual do Professor encontramos subsídios para que possamos oferecer aulas de Arte de qualidade dentro de um processo de vivências dos alunos, pois não podemos abandonar suas experiências.

O depoimento dado pelo(a) professor(a) A e a fala que foi resguardada do(a) professor(a) B reforçam a lacuna que não poderia existir entre os sujeitos que formam esses conjuntos exemplificado por Saviani. Esse autor esclarece ainda que os sistemas educacionais nasceram da necessidade de tornar a educação intencional. Foi assim que ela se organizou em sistema. O sistema educacional é, portanto, o produto, o resultado da educação sistematizada e organizada para determinados fins. Assim, vale ressaltar a necessidade da formação em serviço, aquela que poderá contribuir para um diálogo mais significativo entre o professor e os "recursos didáticos de qualidade" (MINAS GERAIS, 2008, p. 10) que são propostos pelo CRV, com a intenção de reduzir as grandes diferenças que existem entre as várias regiões do estado, no que se refere ao ensino de Arte e à formação para o exercício da cidadania, por exemplo. 


\section{0 planejamento do arte-educador entrelaçado com 0 CBC}

A articulação entre o planejamento do professor e o CBC é uma clara sinalização para verificar a eficácia da proposta curricular. Envolve uma sintonia de tratamentos metodológicos e pressupõe a melhoria na qualidade de ensino. $\mathrm{Na}$ escola, o planejamento realiza-se em diferentes momentos e em várias dimensões. No entanto, no decorrer das observações, ficou visível a dificuldade que o(a)s professore(a)s apresentam, principalmente $\mathrm{o}(\mathrm{a}) \mathrm{s}$ arte-educadore(a)s A e B, com relação ao entendimento da noção de planejamento e plano. Essa dificuldade é apresentada, também, pelas especialistas A e B, que acompanham e supervisionam a operacionalização do plano de ensino.

Verificou-se que o(a)s professores(a)s A e B apresentam conhecimentos para desenvolver apenas os conteúdos procedimentais e, a maioria, voltados para as artes visuais. Com relação aos conteúdos conceituais que se encontram prescritos no planejamento do(a) professor(a), principalmente os relacionados às expressões em artes audiovisuais, dança, música e teatro, não dialogam de maneira sistematizada com o que é realizado em sala de aula e, por sua vez, não condizem com o que é registrado no diário de classe do(a) professor(a), documento que precisa ser verificado e visado pelo supervisor pedagógico.

Esse fato é confirmado também pela opinião dos alunos e alunas de ambas as escolas, ao serem questionado(a)s sobre a área ou áreas especificas da Arte de que consideram ter recebido um ensino significativo até a presente data. Cerca de $65 \%$ dos respondentes afirmam ter recebido, prioritariamente, um ensino voltado para as artes visuais, enquanto $19 \%$ destacam as artes visuais e o teatro, outros $15 \%$, as artes visuais e audiovisuais, e apenas 1\% consideram as artes visuais e a música.

É assim que o alunado percebe o desenvolvimento das aulas relacionadas com o Conhecimento e Expressão em Música, na sala de aula:

Muito pouco, pois foi falado em apenas 2 aulas sobre música em arte (ALUNOS E ALUNAS F1, ESCOLA B)

Não tivemos isso de aula até hoje (ALUNOS E ALUNAS D2, ESCOLA B). Achamos muito importante os aplausos após a apresentação das paródias (ALUNOS E ALUNAS E 2 , ESCOLA A).

Sem importância, porque só apresentamos uma paródia, não tivemos aula 
de música em nenhum outro momento (ALUNOS E ALUNAS J2, ESCOLA A).

Fraquíssimo, só foi pedido para fazer uma pesquisa valendo ponto e a nota nem foi comentada (ALUNOS E ALUNAS G 1 , ESCOLA B), 2009).

Nós não cantamos nem o Hino Nacional como era na outra escola (ALUNOS E ALUNAS H2, ESCOLA A).

Sendo assim, percebe-se que ainda predomina a distância entre as Diretrizes Curriculares do estado e as práticas desenvolvidas nas instituições de Ensino Médio, com relação ao ensino da música.

Considera-se, também, que os resultados do PAAE, expressos por meio dos seguintes documentos: Resumo técnico - Trabalho realizado pela escola, relatório técnico-científico e boletim de desempenho do estudante e do professor ${ }^{1}$, possam contribuir para o desenvolvimento de ações e/ou medidas que favoreçam a articulação do planejamento de Arte com o CBC. No PAAE, está implícita a concepção de que a avaliação deve atuar como mecanismo que estimule o processo de debate e reflexão no âmbito das escolas, bem como no Programa de Intervenção Pedagógica $\left(\mathrm{PIP}^{2}\right)$ e no desenvolvimento do planejamento de cada professor, considerando, especificamente, os conteúdos estabelecidos para cada componente curricular.

No percurso de investigação sobre o PAAE no ensino de Arte, foi relevante verificar o nível de aprendizagem dos alunos com relação às linguagens e expressões artísticas, considerando os resultados obtidos na avaliação realizada no ano de 2008. O objetivo dessa verificação foi identificar se as instituições estão se apropriando ou não das informações disponibilizadas pela SEE/MG sobre a implementação do CBC, além de destacar a opinião do professorado em relação a sua prática diária frente aos resultados da avaliação e suas devidas intervenções. Essas questões constituem-se em pontos-chaves que poderão colaborar para verificar o grau de aproximação do planejamento de Arte com o CBC desenvolvido no interior das escolas.

Dessa forma, a análise foi realizada tendo como referência o desempenho dos alunos nas questões e nos tópicos dos conteúdos do $\mathrm{CBC}$ e complementada por meio das entrevistas realizadas com o(a)s professores(a)s de Arte, e também pelos planejamentos e planos de aulas que foram observados e analisados. 
Os tópicos de conteúdos foram utilizados na elaboração das questões da primeira e segunda avaliações que foram aplicadas aos alunos e ao(à) professor(a) de Arte da escola A, no ano de 2008.

Assim, 16\% dos alunos que se submeteram à primeira avaliação apresentaram habilidades e competências para acertar a questão referente ao tópico de n. 1 e 31\% dos alunos acertaram a questão referente ao mesmo tópico na segunda avaliação, apresentando, então, sinais de melhora e uma possível intervenção pedagógica realizada pelo(a) arte-educa$\operatorname{dor}(a)$.

O que se verifica, a partir da pesquisa, é que as instituições e seus(suas) professore(a)s de Arte não se apropriam, de maneira sistemática, do Programa, e isso é observado claramente no "não" dado como resposta pelo(a) professor(a) B ao ser questionado(a) sobre os resultados do PAAE e se estes contribuíam, de forma efetiva, para fazer uma intervenção em sua prática diária.

Embora a secretária da escola B não tenha encontrado em seus arquivos os resultados das avaliações de Arte do PAAE/2008, foi possível registrar a fala do(a) professor(a) B ao opinar quanto aos resultados de seus alunos no ensino de Arte, apresentados pelo referido Programa: "Excelente, pois tem perguntas aplicadas nesta prova que vão muito além do que uma faculdade oferece e, eles, ficam sempre na média de $50 \%$ dos alunos que acertaram 45\% das questões que se encontram na prova”.

Ao se analisar os aspectos anteriormente mencionados, com relação à escola $\mathrm{B}$, e reconsiderando o "não" que foi mencionado pelo(a) professor(a), assim como o estudo que foi feito levando-se em conta o planejamento dele(a), percebe-se que não houve intervenção significativa para ampliar a aprendizagem dos alunos.

\section{CBC/Arte e a colaboração dos agentes informadores da comunidade}

O ideal é que o horário obrigatório seja usado para que os conteúdos/habilidades específicos de uma determinada área de expressão sejam privilegiados e que sejam utilizados outros horários curriculares para o desenvolvimento de expressões artísticas e a criação de grupos. Dependendo das condições, podem ser escolhidas as áreas artísticas a serem trabalhadas na escola. É bom lembrar que é preferível que o aluno tenha um ensino consistente em uma ou duas áreas de expressão que um ensino deficitário em todas. 
Nesse sentido, os tópicos obrigatórios são referenciais para que o professor aborde os assuntos. O professor poderá escolher os conteúdos que tem mais condições para desenvolver aprofundadamente, através dos tópicos complementares, e contribuir significativamente para a aprendizagem dos alunos em Arte. Como já foi dito, para os conteúdos que não são de domínio do professor, será preciso um esforço do professor e da escola para conseguir membros da comunidade que dominem o assunto e possam colaborar no processo de ensino/aprendizagem dos alunos em Arte como agentes informadores. (MINAS GERAIS, 2008, p. 42-43)

Buscou-se obter informações sobre a opinião dos professores a respeito desses membros, isto é, o grau de participação dos agentes informadores no desenvolvimento do planejamento de Arte. Uma característica observada, no primeiro momento de diálogo com o(a)s entrevistado(a)s, foi o desconhecimento e a falta de informação sobre o que é proposto pelo CBC. $\mathrm{O}(\mathrm{A})$ professor(a) de Arte A mostrou-se surpreso(a) ao dizer: "Não sei se entendi bem, pois nunca tinha ouvido falar disso".

Já o(a) professor(a) B sorriu ao ser indagado(a) sobre as considerações que poderia fazer em relação à colaboração dos agentes informadores frente ao processo ensino-aprendizagem dos alunos, considerando os conteúdos que não são de domínio do(a) arte-educador(a). Assim, disse o(a) referido(a) docente: "Está falando sério, é para rir ou chorar? Em todos esses anos que trabalhei com Arte nunca ouvi falar de alguém que pudesse nos auxiliar nas linguagens em que não temos formação”.

Verificou-se, ainda, que as especialistas de ensino pouco sabem sobre essa parceria, pois não apresentaram argumentos consistentes e tão pouco registros que destacassem a participação de tais membros.

Sendo assim, percebe-se que ainda predomina uma distância entre as políticas desenvolvidas no âmbito da SEE/MG e as práticas desenvolvidas nas instituições de ensino. $O(A)$ professor(a) A faz um desabafo com relação "à utilização de outros horários curriculares para o desenvolvimento de outras expressões artísticas e a criação de grupos de estudos", dizendo:

Como serão realizadas atividades dentro de um horário diferenciado, se tanto professores, alunos, quadros de funcionários da escola e até mesmo horário de funcionamento da escola é tudo programado dentro de um calendário escolar imposto pela SEE. 
Foi salientado ainda que a falta de espaço físico, recursos didáticos e disponibilidade de horários dos alunos são fatores fundamentais que poderão dificultar a implantação e/ou a implementação dessa proposta. Por isso, a fala de uma vice-diretora da escola A foi registrada:

Como podemos ser avaliados e premiados com base em uma estratégia que mal é conhecida e desenvolvida pelas escolas? Estou dizendo isso porque a prova do PAAE não considera a formação do professor de Arte e nem os conteúdos que foram trabalhados nos horários obrigatórios, se assim posso dizer. E o que acontecem com aquelas questões da prova que não foram trabalhadas por falta de conhecimento e domínio do professor? Como fica essa situação, se a escola não conta com os chamados "agentes informadores"?

As questões levantadas pela vice-diretora são relevantes e importantes para subsidiar outros estudos sobre os resultados das avaliações externas realizadas pelo sistema mineiro de ensino. Contudo, é importante ressaltar que

O progresso dos alunos, reconhecidos por meio dessas avaliações, constitui a referência básica para o estabelecimento de sistema de responsabilização e premiação da escola e de seus servidores. Ao mesmo tempo, a constatação de um domínio cada vez mais satisfatório desses conteúdos pelos alunos gera consequências positivas na carreira docente de todo professor (MINAS GERAIS, 2008, p. 9).

Diante disso, será preciso o esforço de todos os segmentos da comunidade escolar que possam contribuir para um ensino de Arte significativo, destacando as diferentes maneiras de viver em sociedade.

\section{O CBC/Arte na perspectiva do educando do Ensino Médio}

A Lei de Diretrizes e Bases da Educação Nacional - 9394/96 - explicita que o Ensino Médio é a "etapa final da educação básica” (art. 36), o que concorre para a construção de sua identidade. Esse nível de ensino passa a ter a característica da terminalidade, o que significa assegurar a todos os cidadãos a oportunidade de consolidar e aprofundar os conhecimentos adquiridos no Ensino Fundamental; aprimorar o educando como pessoa humana; possibilitar o prosseguimento de estudos; 
garantir a preparação básica para o trabalho e a cidadania; dotar o educando dos instrumentos que o permitam "continuar aprendendo", tendo em vista o desenvolvimento da compreensão dos "fundamentos científicos e tecnológicos dos processos produtivos" (art. 35, Incisos I a IV). Portanto, é a etapa final de uma educação de caráter geral, afinada com a contemporaneidade, com a construção de competências básicas, que situem o educando como sujeito produtor de conhecimento e participante do mundo do trabalho. Sendo assim, "Arte, na escola, é a oportunidade de uma pessoa explorar, construir e aumentar seu conhecimento, desenvolver suas habilidades, articular e realizar trabalhos estéticos e explorar sua sensibilidade e seus sentimentos" (MINAS GERAIS, 2008, p. 33).

Com isso, considerou-se importante obter informações sobre a vivência dos alunos e como eles percebem o CBC, no desenvolvimento das aulas de Arte, nesse nível de ensino. No que se refere à perspectiva do alunado com relação ao Ensino de Arte no nível médio, 100\% dos entrevistados responderam que "gostariam que as aulas de Arte pudessem contribuir com o desenvolvimento cultural dos alunos". A conduta sugere, $a$ priori, que os respondentes estabelecem relação dialógica com arte e cultura, assumindo, para além da condição de alunos, a posição de seres humanos que necessitam de conteúdos e estratégias de aprendizagem que os capacitem para

a realização de atividades nos três domínios da ação humana: a vida em sociedade, a atividade produtiva e a experiência subjetiva, visando à integração de homens e mulheres no tríplice universo das relações políticas, do trabalho e da simbolização subjetiva. (BRASIL, 1999, p. 29).

Essa perspectiva, porém, ainda é pouco provável com o tipo de trabalho que vem sendo realizado nas escolas em estudo, principalmente, por elas oferecerem apenas duas horas-aulas semanais e somente no primeiro ano, contando também que $85 \%$ dos entrevistados das duas escolas atribuíram notas abaixo de 6 (seis) para as aulas de Arte recebidas até a série em que se encontram matriculados, desde o Ensino Fundamental.

Os comentários tornam perceptível a ausência de conhecimento mais aprofundado por parte do(a)s arte-educadore(a)s com relação à Proposta Curricular - Arte, em que está inserido o CBC, principalmente quando se trata do Ensino de Arte no nível Fundamental, considerando que, nesse nível, 
a base de formação em arte deve ter sido sólida o suficiente para que, no Ensino Médio, os alunos tenham possibilidade de saberem e participarem de outras manifestações artísticas como, por exemplo, cinema de animação, vídeo-arte, multimídia artística, dentre outras das artes audiovisuais e informáticas (MINAS GERAIS, 2008, p. 35).

Diante dos aspectos mencionados pelo CBC e das respostas apresentadas pelos estudantes, considerando o nível de ensino recebido até então, identifica-se a prática inconsistente nas aulas de Arte. E isso vai de encontro com o que é proposto pelos PCN, que sugerem para o Ensino Médio a promoção e "o desenvolvimento cultural e estético dos alunos com qualidade” (BRASIL, 1999, p. 169). Além disso, ainda salienta que, no âmbito da Educação Básica, o Ensino de Arte pode favorecer nos educandos o interesse por novas possibilidades de aprendizado, de ações e de trabalho com a arte ao longo da vida.

Observa-se que, de forma geral, a arte é considerada pelos alunos como um importante meio na busca de desenvolvimento cultural, embora muitos ainda não tenham despertado o olhar para esse componente curricular, que, sendo bem-planejado, reconhecido e valorizado por todos os que fazem parte do processo ensino-aprendizagem, poderá contribuir para "o fortalecimento da experiência sensível e inventiva dos estudantes, e para o exercício da cidadania e da ética construtora de identidades artísticas" (BRASIL, 1999, p. 169).

A fala da especialista B assinala que

a maioria dos alunos não valorizam esta área, e, poucos são os profissionais que a reconhecem como é estabelecida nas Diretrizes Curriculares Nacionais, assim como nos PCN e CBC. Sem contar que as questões elaboradas por alguns professores, com o objetivo de aferir os conhecimentos artísticos dos alunos, não são criativas e tão pouco contextualizadas.

No que diz respeito à fala da especialista sobre o ensino de Arte frente às Diretrizes Curriculares Nacionais, é importante mencionar que tal "valorização e reconhecimento deveria partir primeiramente do siste$\mathrm{ma}$, que às vezes esquece que esta aula não depende apenas de cuspe $\mathrm{e}$ giz” (PROFESSOR(A) B). Assim, verifica-se que há insatisfação, por parte dos professores, e essa insatisfação ficou visível nas conversas paralelas entre os professores durante os horários de recreio (intervalo para descanso). No entanto, é preciso chamar a atenção dos representantes da 
educação, principalmente do estado de Minas Gerais, destacando a "Reforma Curricular e a organização do Ensino Médio", considerando as quatro premissas apontadas pela Unesco como eixos estruturais (aprender a conhecer, aprender a ser, aprender a conviver, aprender a fazer) da educação na sociedade contemporânea, respeitando, então, a relação dialógica que os estudantes fazem "intuitivamente" entre Arte e Cultura.

Os quatro eixos fundamentais são pilares que exemplificam os objetivos gerais que devem estar presentes na política de melhoria da qualidade da educação. Segundo Zabala (1999), um modo de determinar os objetivos ou as finalidades da educação consiste em fazê-lo em relação às capacidades que se pretende desenvolver nos alunos. Se a escola deve promover a formação integral dos alunos, é preciso definir tais intenções, formulando-as em objetivos gerais, que são mais amplos e mais complexos e poderão ser alcançados ao final do Ensino Fundamental ou Médio, ao final de um ciclo, ou mesmo não se apoiar em apenas uma fase da vida ou em um único lugar.

Tais objetivos ou finalidades, no entanto, não precisam estar formulados no plano de aula do(a) professor(a) de Arte, e tampouco dos demais professores, sendo certo que pertencem ao âmbito do projeto político-pedagógico da escola. Assim, os conteúdos de aprendizagem são instrumentos que possibilitarão as investigações para as questões: o que se deve saber? O que se deve fazer? Como se deve ser?

Coll (1987) estabelece uma divisão que classifica os conteúdos:

(a) Conteúdos conceituais (aprender a aprender);

(b) Conteúdos procedimentais (aprender a fazer);

(c) Conteúdos atitudinais (aprender a ser e conviver).

$\mathrm{Na}$ prática, conhecimentos, habilidades e atitudes são trabalhadas ao mesmo tempo nas situações de ensino e aprendizagem, ainda que, muitas vezes, o(a) educador(a) não tenha consciência de como tais dimensões se entrecruzam e se comportam para resultar em aprendizagem. Dessa forma, a classificação feita pelo autor poderá facilitar as análises e considerações com relação à perspectiva do alunado quanto aos aspectos conceituais, procedimentais e atitudinais na aprendizagem dos conteúdos artísticos estabelecidos para o Ensino Médio. 


\section{Arte como conteúdo conceitual}

Nesta primeira categoria, a abordagem de conceitos, fatos e princípios deve ser articulada com os conteúdos artísticos, de modo a preservar a possibilidade de aprender a conhecer. Esses conteúdos referem-se à construção ativa das capacidades intelectuais para operar com símbolos, ideias, imagens e representações que permitem organizar a realidade.

Dessa forma, a Proposta Curricular em estudo sugere aos(às) arte-educadore(a)s que esses conteúdos sejam trabalhados de maneira que possa favorecer "a compreensão da arte como cultura, do artista como ser social, e dos alunos como produtores e apreciadores" (MINAS GERAIS, 2008, p. 36). A aprendizagem de conceitos se dá por aproximações sucessivas. Para aprender sobre pintura, escultura ou qualquer outro objeto de conhecimento, o aluno precisa adquirir informações, vivenciar situações em que esses conceitos estejam em jogo, para poder construir generalizações parciais que, ao longo de suas experiências, possibilitarão atingir conceitualizações cada vez mais abrangentes.

Buscou-se, contudo, identificar a opinião dos estudantes sobre os conteúdos artísticos apreendidos e a contribuição dos mesmos com relação à construção de conhecimentos em Arte. Cerca de $20 \%$ dos respondentes afirmaram que contribuíram muito, pois as aulas de Arte sempre trataram de conteúdos diversos, em que realizavam produções individuais e coletivas; mas 68\% responderam que foi pouco, pois as aulas de Arte deixaram a desejar, e que os conteúdos e procedimentos artísticos foram tratados de forma superficial; $12 \%$ relataram que as aulas de Arte não apresentaram conteúdos nem procedimentos artísticos que despertassem nos alunos curiosidades e/ou emoções. As especialistas de ensino também comentaram sobre a superficialidade no ensino dos conteúdos artísticos, e agregam esse fato às dificuldades de aprendizagem apresentadas pelos alunos ao chegarem ao Ensino Médio.

A discrepância entre as respostas demonstra que não há articulação consistente entre o ensino e a aprendizagem de conceitos artísticos, e salienta ainda a falta de comunicação existente entre os ensinos Fundamental e Médio, no que se refere ao plano de ensino.

Destaca-se que um(a) professor(a) declarou não ter condições suficientes para trabalhar os conteúdos conceituais, e que essa dificuldade é por não ter tempo de se preparar e tampouco de estudar para ministrar 
suas aulas. Essa situação ficou comprovada também na fala do(a)s aluno(a)s H1, da escola B: "Parece que a professora fica perdida, ela quase sempre esquece o que vai ensinar. Ela mistura muitos assuntos, a nota é 6 porque vale as suas aulas de desenhar e produzir as paródias".

A aprendizagem de conceitos permite organizar a realidade, mas só é possível a partir da aprendizagem de conteúdos referentes a fatos (nomes, imagens, representações), que ocorre, num primeiro momento, por meio da memorização, mas essa não deve ser entendida como processo mecânico e sim como uma etapa que torna o aluno capaz de representar informações de maneira genérica para poder relacioná-las com outros conteúdos; ou seja, trata-se de uma memória significativa.

Portanto, os professores que educam crianças e jovens têm o direito de ser bons professores e precisam ser apoiados em sua formação e valorizados como profissionais, a fim de acompanharem a evolução dos processos educativos. Além disso, é preciso trabalhar para que os educandos possam ter mais interesses e compromissos com a construção de suas aprendizagens, tornando-os sujeitos verdadeiros do processo ensinoaprendizagem.

\section{Arte como conteúdo procedimental}

O aprendizado dos conteúdos conceituais está diretamente relacionado à categoria procedimental. Os procedimentos expressam um saber fazer que envolve tomar decisões e realizar uma série de ações, de forma ordenada e não aleatória, para se atingir uma meta. Assim, os conteúdos procedimentais sempre estão presentes nos projetos de ensino, pois uma pesquisa, um experimento, um resumo, uma maquete, uma escultura, uma colagem são proposições de ações presentes nas salas de aula.

Nesta abordagem, buscou-se conhecer junto aos alunos como esses procedimentos são desenvolvidos na prática de sala de aula e/ou nas atividades extraclasse. Observa-se que o Conhecimento e Expressão em Artes Visuais foi o mais trabalhado nas duas escolas e que a "Expressão e Elementos Formais da Obra de Artes Visuais" (MINAS GERAIS, 2008, p. 62) foi o tema mais explorado. Porém, há comentários, por parte dos alunos, que exaltam as práticas desenvolvidas nas escolas e outros que esperavam mais, enquanto uns não souberam valorizar. 
Por fim, questionados sobre a participação no desenvolvimento de projetos artísticos que tinham causado impacto no seu processo ensino-aprendizagem, bem como em seus colegas de classe e/ou escola, os respondentes apresentaram várias respostas.

Dos diversos depoimentos, tem-se, recorrentemente, destacado o "deixar fazer", que caracterizou o modernismo da arte-educação. Além disso, ficou perceptível que o(a)s professores(as) de Arte acreditam que os alunos já "sabem fazer". Entretanto, alguns alunos relataram que têm muitas dificuldades para participar das atividades artísticas, principalmente daquelas relacionadas com o desenho, embora não tenha sido demonstrada a especificidade do desenho.

Destaca-se, ainda, o entendimento que muitos têm a respeito dos conteúdos procedimentais que deveriam ser desenvolvidos nas aulas de Arte. A maioria ainda os relaciona às práticas que servem apenas para ilustrar os conteúdos que são trabalhados em outros componentes curriculares e/ou para decorar a chamada "Feira de Cultura", realizada em grande parte das escolas onde eles são praticados, na sua maioria aleatoriamente, para se atingir metas.

Por outro lado, manifesta-se certo interesse quanto a esses procedimentos, que são vistos como "de grande importância para os estudantes que cursam o Ensino Médio, principalmente aqueles que cursam esta disciplina no ensino noturno" (ESPECIALISTA, A). Mas Barbosa acredita "na abordagem que torne a arte não só um instrumento do desenvolvimento dos alunos, mas principalmente um componente de sua herança cultural" (BARBOSA, 1991, p. 3). Ela salienta ainda a apreciação, a história e o fazer artístico que devem ser associados desde os primeiros anos do Ensino Fundamental. Sendo assim, os conteúdos procedimentais dessa Área de Conhecimento não podem ser vistos como atividades de relaxamento ou distração.

Foi observado, no entanto, durante algumas aulas, que conteúdos dessa natureza estão sendo abordados, muitas vezes, de maneira equivocada, não sendo tratados como objetos de ensinos que necessitam de intervenção direta do(a) professor(a) para serem de fato aprendidos. Ainda, segundo as observações, ficou em evidência a falta de organização do(a)s professore(a)s de Arte, que, em algumas aulas, solicitaram desenhos, coloridos, colagens e pinturas, sem que fossem considerados os conceitos. Eram solicitados, quase sem nenhuma explicação, e, muitas 
vezes, para completar o total de pontos que deveriam ser atribuídos aos alunos no final do bimestre.

Portanto, é preciso analisar os conteúdos referentes a procedimentos não do ponto de vista de uma aprendizagem mecânica, mas a partir do propósito fundamental da educação, que é fazer com que os alunos construam instrumentos para analisar, por si mesmos, os resultados que obtêm e os processos que colocam em ação para atingir as metas que se propõem.

\section{Arte como conteúdo atitudinal}

Os conteúdos atitudinais permeiam todo o conhecimento escolar. A escola é um contexto socializador gerador de atitudes relativas ao conhecimento, ao professor, aos colegas, às disciplinas, às tarefas e à sociedade. Por isso, é imprescindível adotar uma posição crítica em relação aos valores que a escola transmite implicitamente, por meio de atitudes cotidianas.

Da perspectiva do alunado, são grandes as expectativas com relação à aprendizagem de valores e atitudes, e acredita-se que "a arte poderá abrir portas com carreiras promissoras no novo mercado de trabalho, além de manter um relacionamento sadio entre os colegas e fortalecer os nossos valores - culturais" (ALUNO(A)S B2, ESCOLA B). Ensinar e aprender atitudes requer um posicionamento claro e consciente sobre o que e como se ensina na escola. Ao se tratar desse ensino, entrelaçado com a Arte, tem-se que ele só pode ocorrer a partir do estabelecimento das intenções do projeto educativo da escola. Além disso, o(a) arte-educador(a) deve estar atento(a) para adequar e selecionar conteúdos básicos, necessários e recorrentes.

Por isso, as aulas de Arte devem contribuir para manter "uma relação de cooperação, respeito, diálogo e valorização das diversas escolhas e possibilidades de interpretação e de criação" (MINAS GERAIS, 2008 , p. 51) artística que ocorrem em sala de aula e na sociedade.

Alguns alunos da Escola A, representados pela letra F2, assinalaram que "Acreditam no ensino de Arte, pois este ensino tira vários jovens da rua, ele está contribuindo com vários programas como: Fica Vivo, Vozes do Morro, Valores de Minas, e isso tem interferência no nosso cotidiano". 
$\mathrm{Na}$ fala desses alunos, pôde-se perceber a relação que é feita da Arte com os programas e projetos estratégicos do governo que são oferecidos às escolas que participam do Projeto "Escola Viva, Comunidade Ativa", entre eles o Programa "Valores de Minas", que tem contribuído muito para o desenvolvimento do conhecimento e de expressões artísticas, considerando todas as linguagens da Arte. A oferta de vagas, porém, não atinge nem $2 \%$ dos alunos da escola $\mathrm{A}$ e, segundo o diretor, são muitos os interessados em participar.

Numa conversa eventual com o(a) professor(a) de Arte da escola A, foi relatado por ele(a) que

os alunos que participam do projeto Valores de Minas são mais sensíveis às aulas de Arte, e eles, colaboram muito com as atividades propostas na sala de aula, sempre gostam de liderar tudo que envolve o teatro, a dança e a música na escola, além de apresentarem um comportamento exemplar, respeitando os limites e as normas que são postas.

A observação feita por esse(a) professor(a) ficou evidenciada na fala da aluna $\mathrm{M}$, que expressou, com espontaneidade, durante uma das aulas assistidas pelos promotores da pesquisa: "Lá no Valores, eu aprendo muito com meus colegas, lá a gente aprende de tudo, aprende fazer arte, cantar, dançar, fazer circo. Aprende também sobre os valores e atitudes da vida, inclusive como comportar na família".

Levando-se em consideração a expressão espontânea dessa aluna e as observações feitas nas salas durante as aulas de Arte, pode-se afirmar que a aprendizagem dos conteúdos atitudinais é de natureza complexa e pouco explorada do ponto de vista pedagógico. Segundo os PCN, "muitas pesquisas apontam para a importância da informação enquanto fator de transformação de valores e atitudes" (BRASIL, 1997, p. 52); sem dúvida, a informação é necessária, mas não é suficiente. Para a aprendizagem de atitudes é necessária uma prática constante, coerente e sistemática, em que valores e atitudes almejados sejam expressos no relacionamento entre as pessoas e na escolha dos conteúdos a serem tratados, especialmente, no Ensino de Arte.

Iavelberg afirma que, para trabalhar dentro dessa perspectiva,

o professor de arte precisa de vivências de criação pessoal em arte que lhe propiciem a assimilação de conhecimentos técnicos para realizar a transposi- 
ção didática nas situações de aprendizagem que envolvem o fazer, a apreciação e a reflexão sobre arte como produto cultural e histórico (IAVELBERG, 2003, p. 52).

Essa observação é importante porque, muitas vezes, o professor é absorvido pelo cotidiano escolar, reproduzindo nas aulas ideias alheias, encontradas em planejamentos prontos ou em livros didáticos que não estimulam a reflexão nem contribuem para o enfoque dos conteúdos artísticos sob essa dimensão.

\section{Considerações finais}

O presente estudo procurou compreender o $\mathrm{CBC} /$ Arte como proposta curricular implantada pela Secretaria Estadual de Educação de Minas Gerais, visando a identificar sua implementação sob perspectiva interdisciplinar, para verificar as possíveis contribuições da mesma ao aperfeiçoamento da qualidade do ensino oferecido pelas instituições de Ensino Médio.

O estudo possibilita também identificar a importância que é dada ao conhecimento e às expressões das formas artísticas estabelecidas pela Proposta Curricular, além de destacar a falta de sistematização no desenvolvimento dos conteúdos artísticos ensinados no último nível da Educação Básica.

Ao realizar o trabalho de campo, analisando especificamente a proposta pedagógica e o planejamento do(a)s professore(a)s de Arte, verificou-se que, no primeiro quadriênio de implementação do CBC (20052009), os conteúdos básicos comuns estabelecidos pela Resolução SEE/MG n. 666, de 7 de abril de 2005, são trabalhados parcialmente nas salas de aula. De maneira geral, a prática em sala de aula exercida pelo(a)s professore(a)s não condiz totalmente com o que foi proposto pela PC. Percebeu-se também que há preocupação diária com o desenvolvimento do planejamento; cada aula observada tratava de um assunto específico e, na maioria das vezes, isolado, como se fosse sempre a aula introdutória.

Verificou-se também, nos alunos e alunas participantes, a ausência de uma cultura voltada para o questionamento com relação às aulas dadas e/ou recebidas durante os horários obrigatórios reservados para o ensino de Arte. A participação do(a)s aluno(a)s limita-se a cumprir o que 
é transmitido e exigido pelo(a) professor(a), sem, no entanto, discutir o que fazer e por que fazer. Entretanto, o "como fazer" é somente questionado pelos educandos quando se trata de um procedimento avaliativo em termos de nota. Essa situação torna o processo desvinculado de sentido, fora do que é proposto pelas diretrizes curriculares, que apostam na interdisciplinaridade e na contextualização, em busca de um ensino significativo.

É necessário, portanto, compreender a importância de instalar, nas escolas a cultura do $\mathrm{CBC}$, um conjunto de valores conceituais, atitudes e formas coletivas de condutas que tornem o ato de planejar parte integrante do exercício diuturno das funções que são exercidas no interior das instituições.

Ao realizar as entrevistas com o(a)s professore(a)s e as especialistas de ensino das escolas pesquisadas, verificou-se que, nesse primeiro ano de avaliação do PAAE (2008), a função de proporcionar retorno para as instituições a respeito de seu desempenho não ocorreu na prática das escolas em estudo. De maneira geral, os participantes desconheciam as razões pelas quais os resultados ocorreram daquela forma e não realizaram estudos visando a compreendê-los, e tão pouco consultaram o CRV para a reorganização do trabalho docente. Percebeu-se que houve também desconsideração desses indicadores, tanto por desconhecimento do processo quanto por desvalorização da importância da realização do exame para a instituição.

Há ainda o desconhecimento, por parte da direção, de especialistas, professores e alunos, com relação à participação dos "agentes informadores" no desenvolvimento do planejamento de Arte.

Embora a Proposta Curricular - em que estão os CBC - tenha ressaltado o papel da escola, bem como o do Ensino de Arte, na formação dos cidadãos, tendo em vista a construção de uma sociedade democrática, a efetivação dessa cidadania ainda é um processo em construção, pois as escolas cristalizadas nas propostas curriculares tradicionais e o entendimento que se tem da PC pela maioria dos docentes se identificam mais com a educação no sentido de escolarização, em sua limitada dimensão de distribuição de conhecimentos e na formação de habilidades. Assim, a escola deixa de cumprir seu papel de protagonista nesse processo de construção da ética da cidadania.

Observa-se, então, que teoria e prática estão caminhando separadamente, mesmo que a PC estabeleça conteúdos e estratégias de apren- 
dizagem que capacitem os alunos para "a realização de atividades nos três domínios da ação humana” (BRASIL, 1999, p. 29), a fim de possibilitar a vida em sociedade. Importa destacar que a atividade produtiva e a experiência subjetiva, na prática, não são desenvolvidas. Alguns participantes chegaram a mencionar o "despreparo" do(a) professor(a) de Arte para ministrar alguns conteúdos" e a "aula mal preparada".

O presente estudo pretende oferecer uma contribuição à discussão sobre a implementação da PC, por considerá-lo uma proposta curricular importante para o aperfeiçoamento da qualidade do ensino, no sentido de tornar a rede estadual de ensino de Minas Gerais um sistema de alto desempenho. Trata-se de um assunto de grande complexidade no cenário educacional do estado, sendo importante o desenvolvimento de estudos que discutam e reflitam sobre essa temática. A abordagem dos conteúdos apresentados pelo CBC de Arte tem a vantagem de gerar uma variedade bem maior de pesquisas acadêmicas e talvez angariar maior apoio junto à academia. 


\section{Referências}

AUGUSTO, Rosana. A auto-avaliação institucional na visão dos coordenadores das comissões próprias de avaliação das instituições de ensino superior de Campinas. 2007. 155p. Dissertação (Mestrado em Educação) - Pontifícia Universidade Católica de Campinas, Campinas, 2007.

BARBOSA, A. M. A imagem no ensino da arte. São Paulo, Porto Alegre: Perspectiva/Iochpe, 1991.

BARDIN, Laurence. Análise de conteúdo. Lisboa: Edições 70, 2008.

BRASIL. Ministério da Educação. Secretaria de Educação Média e tecnológica. Parâmetros Curriculares Nacionais: ensino médio: linguagens códigos e suas tecnologias. Brasília: Ministério da Educação/ Secretaria de Educação Média e Tecnologia, 1999.

BRASIL. Ministério da Educação. MEC. Lei de Diretriz̨es e Bases da Educação Nacional (Lei n. 9394/96).

BRASIL. Ministério da Educação. Parâmetros curriculares nacionais: apresentação dos temas transversais, ética/Secretaria de Educação Fundamental. Brasília: MEC/SEF, 1997.

COLL, César. Psicologia X curriculum. Barcelona: Caderno de Pedagogia Editorial. Lara, 1987.

FRANCO, Maria Laura P. B. Análise de conteúdo. Brasília: Líber livro Editora, 2007. (Série Pesquisa, v. 06).

IAVELBERG, Rosa. Para gostar de aprender arte: sala de aula e formação de professores. Porto Alegre: Artmed, 2003.

SAVIANI, Dermeval. Educação brasileira: estrutura e sistema. 7 ed. Campinas: Autores Associados, 1996.

MINAS GERAIS. Secretaria de Estado de Educação. Proposta Curricular. Arte. Belo Horizonte, 2005.

MINAS GERAIS. Secretaria de Estado de Educação. Proposta Curricular. Arte. Belo Horizonte, 2008.

MINAS GERAIS. Secretaria de Estado de Educação. Resolução SEE n. 1025, de 26 de dezembro de 2007. Belo Horizonte, 2007.

MINAS GERAIS. Secretaria de Estado de Educação. Resolução SEE n. 666/2005. Belo Horizonte, 2005.

TRIVINOS, Augusto N. Silva. Introdução à pesquisa em ciências sociais: a pesquisa qualitativa em educação. São Paulo: Atlas, 1987.

ZABALA, Antoni Vidiella. Como trabalhar os conteúdos procedimentais em aula. Porto Alegre: Artes Médicas, 1999. 


\section{ANEXO}

LISTA DE ABREVIATURAS E SIGLAS

CBC - Conteúdo Básico Comum

CRV- Centro de Referência Virtual do Professor

DCN - Diretrizes Curriculares Nacionais

ER - Escolas Referência

LDB - Lei de Diretrizes e Base da Educação Nacional

PAAE - Programa de Avaliação da Aprendizagem Escolar

PC - Proposta Curricular - Arte

PCN - Parâmetros Curriculares Nacionais

PIP - Programa de Intervenção Pedagógica

PNE - Plano Nacional de Educação

SEE-MG - Secretaria do Estado de Educação de Minas Gerais

SRE-Metr.C - Superintendência Regional de Ensino-Metropolitana C

UNESCO - United Nations Educational, Scientific and Cultural Organization.

Recebido: 25/08/2010

Aprovado: 20/10/2011

Contato:

Fundação Educacional de Divinópolis

Instituto Superior de Educação

Centro de Pós Graduação e Pesquisa

Campus de Divinópolis.

Avenida Paraná, 3001

Belvedere II

CEP 35501-170

Caixa Postal 136

Divinopolis, MG

Brasil 
